\title{
A Escola Indígena Wakõmēkwa e seus processos de ensino e aprendizagem na perspectiva da Interculturalidade: Um relato de experiência
}

\author{
La Escuela Indígena Wakõmēkwa y sus procesos de enseñanza y \\ aprendizaje en la perspectiva de la Interculturalidad: Un relato de \\ experiencia
}

\section{Wakõmēkwa Indigenous School and its teaching and learning processes in the perspective of Interculturality: An experience report}

Raquel Castilho Souza ${ }^{1}$

Karyleilla Santos dos Andrade 2

\begin{abstract}
Resumo
Esse trabalho apresenta reflexões de uma pesquisa em andamento referentes às experiências de campo das atividades do Curso de Doutorado em Artes que são realizadas na Escola Indígena Wakõmēkwa, da Aldeia Riozinho Kakumhu, localizada no estado do Tocantins, Brasil. Esta pesquisa é de natureza qualitativa, fundamentada na perspectiva etnográfica, com utilização de procedimentos metodológicos da observação participante. Os autores que sustentam as discussões teóricas e metodológicas perpassam pelos estudos de Bourdieu (1989), Fleuri (2003), Henriques et al. (2007), além dos documentos oficiais que regulamentam a Educação Escolar Indígena. Como resultados preliminares da pesquisa in loco, percebeu-se a manutenção do currículo oficial da educação do estado e a prevalência do uso de material didático em língua portuguesa. Para a comunidade, a escola tem o papel de pertencimento e de aproximação à cultura Xerente. Para eles, a aprendizagem é contínua e diária na aldeia. Ela, como uma "fruta", como consta registrado na fala dos professores, pode espalhar sementes entre os povos indígenas a partir do conhecimento de mundo. Sendo assim, as reflexões realizadas, até o momento, nos permitem concluir que é preciso compreender melhor as práticas pedagógicas, os dispositivos simbólicos e os movimentos identitários presentes na escola Wakõmẽkwa para que a democratização do ensino indígena seja realmente algo significativo para o grupo no seu processo de formação, em busca de uma educação emancipadora e intercultural.
\end{abstract}

Palavras-chave: Cultura. Escola indígena. Interculturalidade. Povo Xerente.

\section{Resumen}

Este trabajo presenta reflexiones de una investigación en marcha referentes a las experiencias de campo de las actividades de doctorado en Artes las cuales vienen siendo realizadas en la Escuela Indígena Wakõmēkwa, da Aldeia Riozinho Kakumhu, ubicada en el estado de Tocantins, Brasil. Esta investigación es de naturaleza cualitativa, fundamentada en la perspectiva etnográfica, con utilización de procedimientos metodológicos de la observación participante. Los autores que sustentan las discusiones teóricas y metodológicas pasan por los estudios de Bourdieu (1989), Fleuri (2003), Henriques et al (2007), como también los documentos oficiales que reglamentan la Educación Escolar Indígena. Como resultados preliminares de la investigación in loco, se percibió el mantenimiento del currículo oficial de la educación. Los materiales didácticos son, en su mayoría, en la lengua portuguesa. Para la comunidad, la escuela tiene un papel de pertenencia y de aproximación a la cultura Xerente. Para ellos, el aprendizaje es continuo y diario en la aldea. Ella, como una "fruta", puede extender

\footnotetext{
${ }^{1}$ Raquel Castilho Souza é Mestre em Educação, Doutoranda em Artes pela Unesp e leciona as disciplinas Psicologia da Aprendizagem e Didática nos cursos de Licenciatura em Filosofia e Teatro, Universidade Federal do Tocantins, em Palmas (TO). Seu email é: raquelcastilho@uft.edu.br.

${ }^{2}$ Karyleilla Santos dos Andrade é Doutora em Linguística e participa do Programa de Pós-Graduação em Letras, câmpus de Araguaína e de Porto Nacional, Universidade Federal do Tocantins. Leciona disciplinas vinculadas aos estudos do Léxico. É Bolsista Produtividade do CNPq PQ2. Seu e-mail é: karylleila@ gmail.com.
} 
semillas entre los pueblos indígenas a partir del conocimiento de mundo. Siendo así las reflexiones realizadas, hasta el momento, nos permiten concluir que es necesario comprender mejor las prácticas pedagógicas, los dispositivos simbólicos y los movimientos presentes en la escuela Wakõmẽkwa para que la democratización de la enseñanza indígena sea realmente algo significativo para el grupo en su proceso de formación, en busca de una educación emancipadora e intercultural.

Palabras claves: Cultura. Escuela Indígena. Interculturalidad. Pueblo Xerente.

\begin{abstract}
This paper presents reflections of an ongoing research regarding the field experiences of the activities of the Doctorate in Arts which are held at Wakõmēkwa Indigenous School, in Riozinho Kakumhu Village, located in State of Tocantins, Brazil. This qualitative research is based on ethnography, and as a methodological procedure it has used participant observation. The authors who sustained the theoretical and methodological discussions permeate the studies of Bourdieu (1989), Fleuri (2003), Henriques et al. (2007), in addition to the official documents that regulate the indigenous school education. As preliminary results of this in loco Research, it was perceived the maintenance of the official curriculum of state education, and the prevalence of the use of didactic material in Portuguese Language. For the community, the school has the role of belonging and approximation to the Indigenous Xerente Culture. For the community, learning is a continuous and daily process, which happens in its village. As recorded in the speech of its teachers, learning is seeing "as a fruit", because it can spread its seeds among indigenous people from the knowledge of the world. Thus, the reflections made allow us to conclude that we need to better understand the pedagogical practices, the symbolic devices and the identity movements present in the Wakõmẽkwa School, so that the democratization of teaching becames actually something significant for the group in its formation process, in search of an emancipating and intercultural education.
\end{abstract}

Keywords: Culture. Indigenous School. Interculturality. Xerente People.

\title{
1 Introdução
}

O presente relato de experiências é parte das atividades de pesquisa do Doutoramento Interinstitucional em Artes (Dinter UNESP/UFT), vinculado ao Programa de Pós-graduação em Artes da Universidade Estadual Paulista Júlio de Mesquita Filho. Este trabalho é resultado do estudo que envolve discussões sobre o ensino e aprendizagem na perspectiva da interculturalidade na Escola Estadual Indígena Wakõmẽkwa, localizada na Aldeia do Riozinho Kakumhu, na região do Município de Tocantínia, estado do Tocantins, na comunidade dos Povos Xerente.

A pesquisa tem como objetivo identificar se a educação formal, desenvolvida para os povos indígenas, está sendo aplicada na perspectiva da interculturalidade, conforme previsto nos documentos oficiais da educação. Para isso, se faz necessário tentar responder os seguintes questionamentos: "O currículo indígena é proposto em uma perspectiva da interculturalidade, e os saberes cotidianos se fazem presentes no ensino da escola Wakõmẽkwa?"

Este estudo é de natureza empírica, com abordagem qualitativa e de cunho etnográfico. Essa escolha se justifica pela necessidade de compreender, in loco, o contexto em que pesquisadores e professores estão presentes, além de entender o sistema de valores e 
modos de vida, as relações de poder, o silenciamento e as resistências que influenciam a comunidade indígena.

Como sujeitos de pesquisa, temos oito professores indígenas que estão na regência da escola em questão. Está sendo utilizada, nessa primeira fase da investigação, a técnica de pesquisa da observação participante, como possibilidade de identificação e reflexão do objeto. Essa técnica tem possibilitado o contato direto com o campo de pesquisa e as experiências cotidianas dos sujeitos. Como resultado, obtivemos o Diário de Campo.

Apresentamos, nesse texto, algumas impressões, enquanto pesquisadoras, por meio de observações da rotina escolar e das aulas de Artes nas turmas do Ensino Fundamental (primeira fase, do $1^{\circ}$ ao $5^{\circ}$ anos - vespertino).

\section{Interculturalidade, escola e ensino no processo de aprendizagem e suas interfaces no contexto indígena}

Com as relações associadas ao saber escolar, o aluno se torna sujeito, um agente ativo e passa a ser capaz de dar sentido a tudo que vivencia na escola uma vez que a relação com o saber trata da relação consigo mesmo, com o outro e com o mundo. Consequentemente, essas relações podem contribuir para a constituição da identidade do sujeito-aluno, para que ele tenha melhor condições se compreender a si mesmo diante do outro e de manter relações de troca com agentes de sua cultura e de outras culturas, pela interpretação do mundo que o cerca, sem perder sua essência.

O professor tem influência no processo de ensinar e aprender no ambiente escolar e, por isso, é necessário que ele esteja preparado quanto ao que vai ensinar e a partir de quais métodos e técnicas de ensino e aprendizagem. Ele tem que ter clareza sobre o que pretende ensinar, com objetivos educativos definidos, em sinal, inclusive, de respeito as suas origens. Um dos professores da escola pesquisada relatou que "[...] a dificuldade está relacionada ao ensino devido à falta de livro didático na linguagem Akwẽ. Os professores têm conteúdo, mas não sabem como ensinar."

Entretanto, o ambiente escolar poderá ser transformado pelo desejo de seus agentes em superar todas as dificuldades diárias que são enfrentadas e, como pesquisadoras, sentimos essa superação desde a primeira visita à escola. A Figura 1 nos mostra a Escola Estadual Indígena Wakõmẽkwa, após a segunda etapa da Construção. 


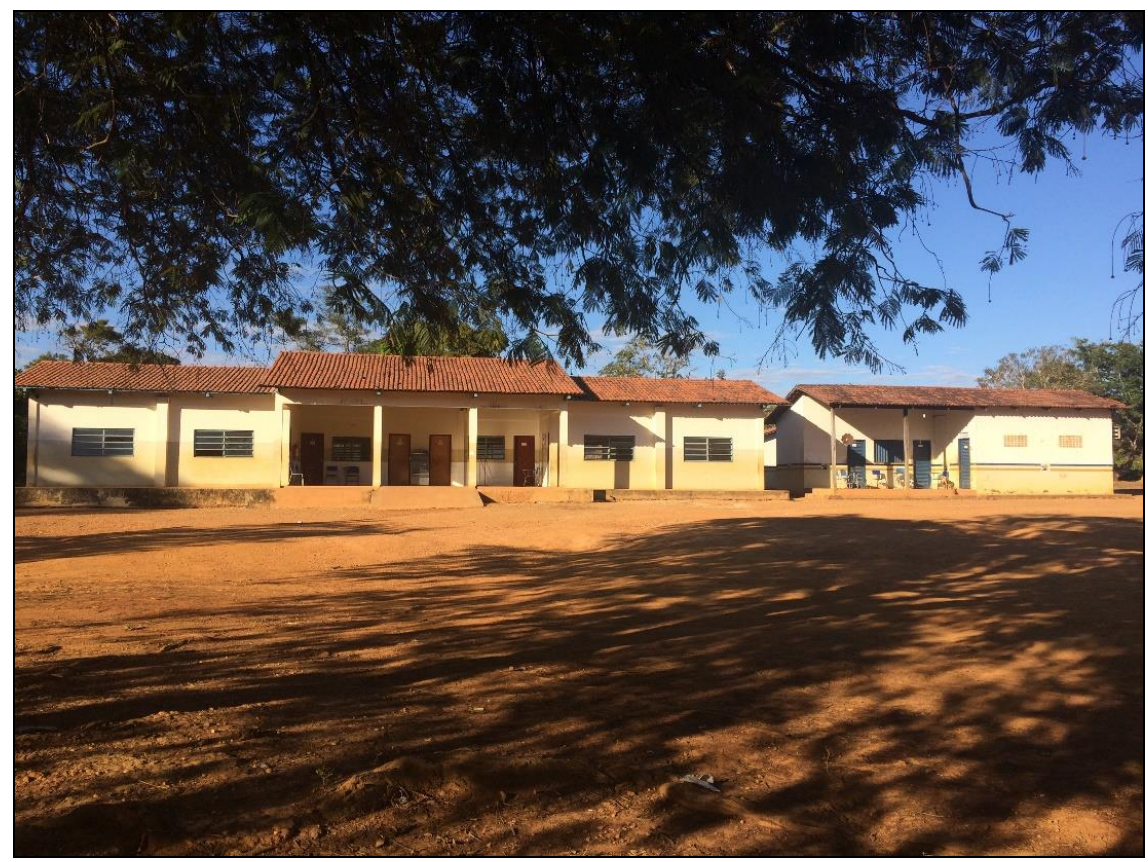

Figura 1: Escola Estadual Indígena Wakõmẽkwa: depois da segunda etapa da Construção Fonte: Souza (2019, p. 63).

O aprender indígena, entendido aqui como os saberes do povo, inicia-se de maneira informal, dentro de casa, no pátio, nas relações de parentesco, nos rituais, prolongando-se até os dias de hoje. Para eles, a escola é concebida como extensão da comunidade, porque é o lugar onde se aprende, se ensina, se conhece, se transmite saberes, podendo ser um lócus de revitalização das práticas da cultura Xerente. Os professores indígenas superam desafios cotidianamente para buscarem conhecimentos que possam auxiliá-los em sala de aula.

$\mathrm{Na}$ primeira fase da pesquisa, procuramos identificar as demandas e o sentido da escola para os professores e para a comunidade escolar. Identificamos que a escola pesquisada fornece alimentos todos os dias, sendo a maioria industrializada. A evasão é mais comum na Educação de Jovens e Adultos (EJA). O livro didático adotado na escola é o disponibilizado pela Secretaria de Estado da Educação, Juventude e Esportes (SEDUC), portanto, os alunos não possuem material didático específicos na língua Akwẽ. Até o momento, foi identificado apenas um dicionário Escolar Xerente-Português/Português-Xerente, de 1994, e uma apostila identificada como "Escrita Xerente: a sílaba" para professores Xerente. A escola está em processo de construção do Projeto Político Pedagógico (PPP), e os professores relataram a realidade vivenciada por eles a partir do ponto de vista de cada um. Esse relato ocorreu no decorrer de uma reunião solicitada pelos professores e pela gestão da escola. Nesse momento, todos se apresentaram, informando as disciplinas e as séries pelas quais eram responsáveis. 
Um dos professores destacou que a educação escolar Akwẽ é complexa, porque eles lidam com dois conhecimentos, com duas culturas. No entendimento do professor, para aprender, é preciso praticar, gerando um impacto, pois precisam ter contato com esses dois conhecimentos e duas línguas. Assim, a comunidade quer uma educação que valorize os dois conhecimentos para saber conviver com a outra cultura e, consequentemente, facilitar a comunicação, até porque eles são povos de fronteiras. Vivem no limiar entre diferentes tradições: a do povo Xerente e a do não-indígena ou povo "branco" (como eles chamam). Esse processo, na escola, está em construção. Existe a necessidade de planejar essa escola a partir dessa perspectiva e reconhecimento e interação entre essas duas culturas.

Vale destacar, aqui, que os colaboradores da Escola a percebem como um lugar simbólico para a comunidade, que deve contribuir efetivamente na formação das crianças, uma vez que, por meio dela, é possível conhecer, (re)viver e revitalizar a tradição, bem como as crenças, ritos, músicas e, principalmente, estudar a própria língua. A escola, para a comunidade, está presente na vida deles. Os professores destacam, nas suas falas, que escola serve para

[...] revitalizar a cultura [e isso] não é resgatar. Valorizar a cultura, fortalecer a cultura e identidade, com várias ações por meio da arte, da geografia, da cultura; conhecimento. Escola é conhecimento. Dentro da escola a gente consegue conhecer. Conhecimento seria aprendizagem. Adquire conhecimento pela aprendizagem. aquisição da língua escrita - língua Akwẽ e portuguesa; porque a escola é bilíngue e intercultural; - preservar a cultura; - interculturalidade; - para saber conviver com a outra cultura; - para facilitar a comunicação; - valorização da medicina tradicional indígena.

No estado do Tocantins, a legislação para educação indígena busca assegurar uma oferta de um Ensino Fundamental regular com a utilização das línguas maternas e programas, cuja elaboração deve incluir comunidades, organizações e entidades. Como foi observado, existem programas de implantação e de formação de profissionais para uma educação intercultural nas comunidades indígenas, mas sem o envolvimento desses sujeitos, porque a rotina escolar não tem contemplado o previsto em lei no Estado em relação à Escola Estadual Indígena Wakõmẽkwa (TOCANTINS, 1998).

Os professores lidam, cotidianamente, com um índice muito alto de reprovação dos alunos indígenas que vão para as escolas nos municípios vizinhos às comunidades, em decorrência da dificuldade de se adaptarem com o uso, a fala e a escrita da sua segunda língua, a portuguesa. Segundo os professores, as supervisões da SEDUC não ocorrem regularmente em relação às atividades na escola, o que causa falta de suporte. Além disso, 
eles relatam que não tem ocorrido capacitação e formação continuada de modo regular. A equipe da SEDUC vai à escola uma vez ao ano, e a Diretoria Regional de Ensino (DREA) realiza supervisão esporádica.

A primeira lei estadual $n^{\circ} 1.038$, de 22 de dezembro de 1998, esclarece a obrigação do Estado em relação à Educação para as Sociedades Indígenas, garantindo os seguintes itens: bilinguismo para a afirmação das culturas e línguas indígenas; preparação para compreensão e reflexão crítica da sua realidade sociohistórica e da sociedade envolvida, bem como sobre a condição para sua autodeterminação; formação de professores indígenas; e viabilização de elaboração de materiais escritos pelos próprios indígenas que retratem seu universo sociohistórico e cultural (TOCANTINS, 1998).

Segundo Fleuri (2003), a escola indígena intercultural, em sua prática, deve incluir o caráter da sua cultura tradicional, assim como das outras, principalmente em suas ações pedagógicas dando sentido à história e tradição do seu povo, reafirmando, portanto, o anseio dos professores indígenas. Assim sendo, estariam em seus processos de ensino, incentivando a valorização dos conhecimentos e pedagogias dos povos indígenas, das línguas maternas, da interculturalidade, primando pela autonomia escolar, inclusive colaborando na elaboração dos currículos oficiais e calendários (HENRIQUES et al., 2007).

Alguns dos professores questionam se os índios perderam a cultura ou se ela está apenas "esquecida". Para eles, a escola deve se apropriar dessas questões e refletir sobre elas, pois refletir sobre a cultura é reconhecer a diversidade dos povos, das nações, das sociedades e dos grupos que são compostos por diferentes agentes sociais. Toda comunidade cultural tem sua história particular, que é reflexo de sua própria cultura, mesmo que o grupo se relacione com outras culturas (SANTOS, 1994).

Um dos professores índios destaca que "[...] a escola indígena deve ser diferenciada, mas que ela é diferenciada somente pela cultura, práticas culturais e a língua, porque o conhecimento é universal, e o sistema não-indígena está na escola indígena. E a diferença deve somar a outra diferença." Contrapondo um pouco a fala desse professor, o que percebemos, com os resultados preliminares dessa pesquisa de campo, é de que a escola indígena continua sendo colonizada, ora pelo currículo formal, ora pelo regimento escolar.

Por outro lado, o currículo do Estado vem atendendo ao especificado nas bases legais em nível federal, como o descrito nos Referenciais para a Formação de Professores Indígenas (RCNEI) - (BRASIL, 2002). As disciplinas Língua Indígena, Artes e Cultura, e História e Cultura Indígenas estão previstas e são desenvolvidas regularmente nas atividades da escola 
pesquisada. Os professores, ao seu modo e com suas dificuldades pedagógicas, têm mantido presente sua cultura no ambiente escolar, na tentativa de preservar as tradições indígenas.

A SEDUC tem procurado atender às especificidades culturais e identitárias de cada povo, estabelecendo diretrizes e normas para regimentar a educação indígena no estado do Tocantins, obedecendo à Lei 9.394/96 que diz que as escolas no Estado deverão ser específicas, bilíngues e interculturais (TOCANTINS, 2007).

As turmas são multisseriadas, o que aumenta a dificuldades em relação a questões metodológicas. O sentimento de pertencimento à escola é algo perceptivo também. Segundo os professores, estudar é aprender a respeitar, a dialogar e a conhecer mais a cultura e a língua para poder preservá-la. A Escola Estadual Indígena Wakõmẽkwa, como espaço formal, serve para buscar conhecimento, resgatar a tradição e as crenças.

Segundo Bourdieu (1989), a escola é em um espaço social onde a cultura se revela e se constitui pelos agentes que nela se relacionam. Esses agentes representam grupos que se caracterizam por princípios particulares de visão e pelo seu modo específico de ver o mundo, nesse caso, o povo akwẽ e a cultura Xerente. Suas histórias caracterizam o modo particular de cada grupo social, que estão refletidas na história de cada um e que se manifestam na sua cultura.

A escola indígena é a oportunidade de reforçar esse conhecimento cultural. Nela, são ensinadas a escrita da língua Akwẽ e a da língua portuguesa. Na fala dos professores, a escola é bilíngue e intercultural, sendo um lugar de afetividade, enquanto lar da cultura Xerente, de apropriação, de conhecimento e de sabedoria. Portanto, a escola tem o papel de pertencimento e de aproximar a cultura do povo Xerente. A escola está para a comunidade, assim como a comunidade está para a escola. A aprendizagem na comunidade é contínua e diária. A escola, "como uma fruta", no dizeres de um dos professores, pode espalhar sementes entre os povos indígenas a partir do conhecimento.

Percebemos, em vários momentos, ao observarmos a rotina escolar, alguns indícios em relação a essa questão. Dentre eles, está a falta de material pedagógico e didático na língua akwẽ. Isso tem aumentado a dificuldade dos professores em lidar com os dois conhecimentos no processo de ensino. Ao mesmo tempo em que precisam dar aula na língua materna para preservar a cultura, as crianças estão tendo contato direto com língua portuguesa precocemente, ainda na alfabetização, por falta de material em akwẽ. Em muitas ações, há o predomínio do português em detrimento do Akwẽ.

O Art. 53, da Lei No 2.139/2009, Seção III Da Educação Escolar Indígena, diz que o Sistema Estadual de Ensino deve oferecer às comunidades indígenas, dentro das 
possibilidades, o ensino fundamental e médio bilíngue e intercultural, respeitando a diversidade sociocultural. Já o Art. 54 procura assegurar recursos específicos no Orçamento Geral do Estado destinados à Educação Indígena. Na alínea I consta que o Estado deverá garantir o desenvolvimento de metodologias específicas do processo de educação escolar das comunidades indígenas, especialmente as metodologias referentes ao processo de aquisição da língua escrita materna e do português como segunda língua, sendo a primeira, como veículo dos conhecimentos de cada cultura, e a segunda, como veículo dos conhecimentos universais. No entanto, o que identificamos na análise dos dados da pesquisa, até o presente momento, é que a escola, com a falta de materiais didáticos e pedagógicos na língua materna Akwẽ, tem introduzido a segunda língua (Língua Portuguesa) desde o $2^{\circ}$ ano do Ensino Fundamental.

A legislação, especialmente no que tange ao currículo da educação escolar indígena, destaca, predominantemente, que os sistemas de ensino e aprendizagem, que lhes são próprios, sejam interculturais, diferenciados e bilíngue. No currículo, existem os conteúdos universais, porém, os específicos dos povos indígenas devem ser prioridade, primando pelo ensino da língua indígena como a primeira língua. Isso exige dos projetos educacionais e seus princípios que estejam em consonância com a realidade da comunidade escolar indígena, em uma perspectiva da interculturalidade (BRASIL, 2017).

Considerando a perspectiva intercultural, o Estado deveria, então, promover ações escolares que possibilitassem trabalhar "[...] com valores, práticas e saberes tradicionais da comunidade, visando garantir o acesso a conhecimentos da sociedade envolvente, efetivados por atividades curriculares significativas e contextualizadas às experiências dos estudantes e suas comunidades.” (ALMEIDA, 2012, p. 158).

Identificamos que, em termos de planejamento, o previsto na legislação federativa é contemplado em nível estadual na descrição das ações a serem executadas no plano estadual de educação com apoio municipal, priorizando os aspectos relacionados apenas à Educação Indígena. Eles discutem a Educação Indígena para os povos brasileiros, que deve ser diferenciada, bilíngue e intercultural, atendendo às especificidades de cada povo (ALMEIDA, 2012; SANTOS, 2009). Se esses conhecimentos fossem contemplados na prática, os conhecimentos e saberes indígenas seriam respeitados e valorizados. Santos (2005) destaca o seguinte, em relação a isso:

No entanto, estamos diante de um descompasso entre o projeto de uma educação diferenciada e sua efetivação nas escolas indígenas. Pode-se citar, como exemplo, a insuficiente acolhida e compreensão por parte dos órgãos oficiais, de calendários, 
currículos e regimentos específicos, organizados por comunidades indígenas. (SANTOS, 2005, p. 4)

Mesmo que as propostas sejam elaboradas pelos representantes indígenas, se elas não são atendidas em suas especificidades, de nada adianta tantas normas e regulamentações. É preciso uma união entre projetos, para que possam, de fato, colaborar no fortalecimento dos costumes e culturas tradicionais dos povos indígenas, por meio de um diálogo efetivo, entre agentes indígenas não-indígenas para uma educação intercultural.

Percebe-se que a Escola Estadual Indígena Wakõmẽkwa passa por uma situação de vulnerabilidade, diante das condições atuais que se encontra e com as dificuldades diárias encontradas pelos professores para desenvolverem suas atividades. Observou-se também que os sistemas e dispositivos que se movimentam no interior das suas estruturas sociais são reflexos de práticas, tanto individuais quanto coletivas e que estabelecem rotinas corporais e mentais (THIRY-CHERQUES, 2006). Os sistemas, que podem ser estáveis ou removíveis, se tornam princípios geradores e organizadores das práticas e representações de uma classe de suas condições de existência. Portanto, o currículo, segundo Moreira e Candau (2014,) deve promover um espaço para fazer pensar envolvendo discussões sobre arte, cultura e filosofia. Diante da realidade evidenciada na escola, é necessária uma desconstrução do currículo, para que ele seja o lugar de produção de cultura.

Portanto, é urgente que haja uma reflexão sobre o currículo da escola indígena intercultural, que envolve os processos de ensinar e de aprender. Nessa discussão, é primordial a participação dos agentes sociais, dos gestores da educação e dos responsáveis pela aplicação da legislação e pela elaboração de políticas públicas eficazes.

\section{Conclusões}

Atualmente a educação indígena vem sendo alvo de muitas discussões no campo educacional. Isso significa que vários estudos e pesquisas devem acontecer a fim de transformar as resistências e os paradigmas com relação aos povos indígenas que têm direitos resguardados por lei, porém, esses direitos não estão sendo atendidos e nem respeitados na prática. É preciso garantir uma formação de professores indígenas críticos, autores e coautores dos seus conhecimentos, que vá além do interesse capitalista.

Dessa forma, é preciso dar continuidade à pesquisa, de modo que se possa compreender melhor as práticas pedagógicas, os dispositivos simbólicos e os movimentos presentes na comunidade da Escola Estadual Indígena Wakõmẽkwa, para que a democratização do ensino indígena seja realmente significativa para a sociedade no seu 
processo de formação, em busca de uma educação emancipadora. Então, ouvir os principais sujeitos, sociohistóricos e políticos, que (con)vivem nesse cenário, é essencial para que se possa compreender o seu papel no processo de formação do seu povo, que envolve relação social, cultura tradicional e histórias marcadas por processos evolutivos, porém discriminatórios.

Nesse contexto, vale destacar a necessidade de conhecer o lugar, as histórias e os saberes da escola Wakõmẽkwa e da comunidade de Riozinho. Explorar, portanto, o espaço da comunidade é sentir o trabalho coletivo que é desenvolvido cotidianamente. É preciso ver a cultura enraizada na expressão do rosto, na comunicação, no sorriso, no fazer do dia a dia, como no preparo do alimento. Esse lugar é pulsado pela força da natureza tão presente no espaço físico em que estão e pelas lutas por uma vida digna.

\section{Referências}

ALMEIDA, S. A. de. A Educação Escolar Apinayé na Perspectiva Bilíngue e Intercultural. In: ALMEIDA, S. A. de. A educação escolar Apinayé de São José e Mariazinha: um estudo de Caso sociolinguístico. Goiânia: Ed. América, 2012, p. 153-233.

BRASIL. Referenciais para a formação de professores indígenas. Secretaria de Educação Fundamental. Brasília: MEC; SEF, 2002.

BOURDIEU, P. O poder simbólico. Tradução de Fernanda Tomaz. Rio de Janeiro: Editora Bertrand Brasil, 1989.

FLEURI, R. M. Intercultura e educação. Revista Brasileira de Educação, Rio de Janeiro, v. 10, n. 23, p.16-35, maio/ago. 2003.

HENRIQUES, R. et al (Orgs.). Educação Escolar Indígena: diversidade sociocultural indígena ressignificando a escola. Ministério da Educação, Secretaria de Educação Continuada, Alfabetização e Diversidade. Brasília: Sedac/MEC, 2007.

MEC. Base Nacional Comum Curricular. $3^{\mathrm{a}}$ versão revista. Ministério da Educação. Brasília, 2017.

MOREIRA, A. F.; CANDAU, V. M. Currículos, disciplinas escolares e culturas. Petrópolis, RJ: Vozes, 2014.

SANTOS, J. L. dos. O que é Cultura. 15. ed. São Paulo: Brasiliense, 1994.

SANTOS, P. M. C. Fronteiras interculturais: especificidades da educação indígena no Tocantins. In: MATA, S. R. da; MOLLO, H. M.; VARELLA, F. F. (Orgs.). Anais do III Seminário Nacional de História da Historiografia: aprender com a história? Ouro Preto: Edufop, 2009. 
SANTOS, P. M. C. Educação Indígena: perspectivas de interculturalidade nas demandas e propostas dos povos indígenas do Tocantins. XXII Simpósio Nacional de História - ANPUH. Londrina, 2005.

SOUZA, R. C. A Educação Escolar Indígena Intercultural e o Ensino das Artes: um olhar sobre as práticas da Escola Wakõmẽkwa na Comunidade Riozinho Kakumhu - Povo Xerente - Tocantins. 2019. 258f. Tese de Doutorado em Artes. Universidade Estadual Paulista "Júlio de Mesquita Filho" - Unesp, SÃO PAULO, 2019.

THIRY-CHERQUES, H. R. Pierre Bourdieu: a teoria na prática. RAP, Rio de Janeiro, v. 40, n. 1, p. 27-55, Jan./Fev. 2006. Disponível em:

<http://www.scielo.br/pdf/rap/v40n1/v40n1a03.pdf>. Acesso em: 2 abr. 2018.

TOCANTINS. Lei $n^{\circ} 1038$, de 22 de dezembro de 1998. Publicado no Diário Oficial $\mathrm{n}^{\circ} 753$.

Governador do Estado do Tocantins - Assembleia Legislativa do Estado do Tocantins.

Disponível em: < www.al.to.leg.br/legislacaoEstadual?pagPaginaAtual=97>. Acesso em: 27 dez. 2018.

TOCANTINS. RESOLUÇÃO № 78, DE 20 DE JUNHO DE 2007. Governador do Estado do Tocantins - Secretaria da Educação e Cultura, Conselho Estadual de Educação. Disponível em: <http://fncee.com.br/wp-content/uploads/2014/09/res-078-2007-INDIGENA.pdf>. Acesso em: 27 dez. 2018.

TOCANTINS. Lei $N^{\circ} 2.139$, de 3 de setembro de 2009. Publicada no Diário Oficial $n^{\circ} 2.970$. Dispõe sobre o Sistema Estadual de Ensino e adota outras providências. Governador do Estado do Tocantins - Assembleia Legislativa do Estado do Tocantins. Disponível em: <www.al.to.leg.br/arquivo/30465>. Acesso em: 27 dez. 2018. 